Research Article

\title{
Effects of Surfactant Warm-Mix Additives on the Rheological Properties of High-Viscosity Asphalt
}

\author{
Jingtao Shi $\left(\mathbb{D},{ }^{1,2}\right.$ Weiyu Fan $\left(\mathbb{D},{ }^{1}\right.$ Yi Lin $\mathbb{D},{ }^{1}$ Pinhui Zhao $\mathbb{D},{ }^{1}$ and Jian Ouyang $\mathbb{D}^{3}$ \\ ${ }^{1}$ State Key Laboratory of Heavy Oil Processing, College of Chemical Engineering, China University of Petroleum (East China), \\ Qingdao 266580, China \\ ${ }^{2}$ Petrochina Fuel Oil Company Limited Research Institute, Beijing 100195, China \\ ${ }^{3}$ School of Transportation and Logistics, Dalian University of Technology, Dalian 116024, China
}

Correspondence should be addressed to Weiyu Fan; 15853256892@139.com, Pinhui Zhao; zhaopinhui08@163.com, and Jian Ouyang; ouyangjian@dlut.edu.cn

Received 20 January 2020; Accepted 6 March 2020; Published 25 April 2020

Guest Editor: Meng Guo

Copyright (c) 2020 Jingtao Shi et al. This is an open access article distributed under the Creative Commons Attribution License, which permits unrestricted use, distribution, and reproduction in any medium, provided the original work is properly cited.

In order to evaluate the possibility of the application of warm mixing technology in high-viscosity asphalt mixture, in this paper, the effects of surfactant warm-mix additives (WMAs) on physical and rheological properties of high-viscosity asphalt (HVA) which was prepared with self-developed $\mathrm{SBS} / \mathrm{C}_{9}$ petroleum resin blends (SPR) modifier were measured. The results indicate that the addition of WMA can decrease the viscosity and softening point but improve the penetration and ductility of warm-mix HVA. With the increase of the content of WMA, the modulus, failure temperature, viscosity, and recovery rate of warm-mix HVA all increased at first and then decreased, and the maximum value appeared when the modifier content was $1.0 \%-1.5 \%$. Moreover, when the amount of WMA is $1.5 \%$, the low-temperature performance of warm-mix HVA reaches the best value. Thus, the amount of WMA is of great importance for the warm-mix HVA, and in order to achieve ideal rheological properties, the recommended amount of WMA is $1.0 \%-1.5 \%$. Considering economic improvement and environmental protection, WMA could be an alternative for increasing the workability of HVA.

\section{Introduction}

Porous asphalt pavement has various advantages such as a high void ratio, large frictional resistance attributed to the rough surface, skid and rutting resistance, and sound absorption and noise reduction $[1,2]$. Therefore, it can reduce the thickness of water film on the pavement, water spray, and noise in wet weather, thus improving the skid resistance and enhancing driver safety [3-5]. Thus, porous asphalt pavements have been widely used in many countries [6]. Due to functional requirement of drainage, it is necessary to realise a void ratio greater than $18 \%$ through the formation of an interlocked skeleton structure by increasing the amount of coarse aggregates and reducing the amount of fine aggregates when designing porous asphalt mixtures; However, the structure has high internal frictional resistance and a low cohesion, and the bonding property of the binder can be crucial if it is expected to acquire a large strength and resistance to external failure $[7,8]$. Ordinary modified asphalts fail to satisfy the requirements for practical application and therefore the application of HVA is inevitable $[9,10]$. Based on many years of practical experience in Japan, the concept of HVA was proposed to improve the long-term performance and durability of porous asphalt mixtures. For HVA, the dynamic viscosity at $60^{\circ} \mathrm{C}$ is a key parameter [11-13]. The higher its value, the better the high-temperature performance, deformation resistance, and cohesiveness of asphalt binders [9]. However, with the increase of dynamic viscosity at $60^{\circ} \mathrm{C}$, the viscosity of $\mathrm{HVA}$ at $135^{\circ} \mathrm{C}$ is also higher than that of the ordinary modified asphalt binder [14]. There is no doubt that this problem will increase the difficulty of construction, thus making asphalt mixtures harder to be produced and compacted for construction [15]. However, as HVA can satisfy machinability requirements, it is necessary 
to heat the HVA to a higher temperature, which is likely to accelerate the aging of asphalts and increases energy consumption and harmful gas emission during construction. This hinders the development and application of HVA to some extent [16].

Warm-mix asphalt technology is considered to be an effective solution to improve the workability of asphalt mixture and control the construction temperature at a low level by decreasing the viscosity of asphalts. Compared with hot-mix asphalt technology, warm-mix asphalt technology can lower the mixing and compaction temperatures, thus saving energy consumption and reducing the emission of harmful gas. Therefore, warm-mix asphalt technology can probably be classified as green technology for road construction $[17,18]$. The application of warm-mix asphalt technology to the porous asphalt pavement can not only improve functional pavements but also can be beneficial to the environment. However, whether or not the application of different kinds of warm-mix asphalt technology exerts unfavourable effects on the performance of finished HVA is waiting to be further explored. Rodríguez-Alloza et al. [19] evaluated the influence of four types of warm-mix additives (Sasobit, Asphaltan A, Asphaltan B, and Licomont BS 100) on the performance of the crumb rubber modified asphalt (CRMA). The results showed that the WMAs can successfully reduce the viscosity of CRMA, improve the softening point, and lower the penetration. Additionally, the four types of WMAs do not exert great influence on the elastic recovery and ductility of asphalts at $25^{\circ} \mathrm{C}$. Sanchez-Alonso et al. investigated the influences of three kinds of warm-mix asphalt technology (including chemical WMAs, organic WMAs, and foamed asphalt) on the performance of asphalt mixtures. The results revealed that the addition of WMA reduces the construction temperature. At the temperature adopted in the experiment, compared with hot-mix asphalt mixture, the water sensitivity of warm-mix asphalt mixture is improved [20]. Podolsky et al. explored the influences of biological base WMA on the compactness and low-temperature cracking of matrix asphalt and polymer-modified asphalt mixture. They suggested that, compared with a hot-mix asphalt mixture, the addition of WMA reduces the construction temperature and still generates similar compaction performance. Furthermore, WMA polymer-modified asphalt mixture is similar to hot-mix asphalt mixture in lowtemperature cracking terms [21]. Zheng et al. investigated the influences of three types of WMAs (RH, EC-120, and Sasobit) on dynamic viscosity at $60^{\circ} \mathrm{C}$, Brookfield viscosity at $135^{\circ} \mathrm{C}$, high-temperature rheological properties, and lowtemperature creep properties of styrene-butadiene-styrene (SBS) HVA. The results suggested that these WMAs significantly reduce the high-temperature viscosity $\left(135^{\circ} \mathrm{C}\right)$ of SBS HVA asphalts while EC-120 and Sasobit decrease the absolute viscosity $\left(60^{\circ} \mathrm{C}\right)$. Moreover, EC-120 can increase the high-temperature rheological properties and improve the low-temperature creep properties of asphalt mixtures [6]. Frigio et al. explored the moduli and fatigue performance of warm-mix porous asphalt mixture before and after aging process. They found that warm-mix asphalt technology lowers the construction temperature and reduces the elastic modulus of the mixture, with no influence on the fatigue performance of mixture after long-term aging [22]. However, at present, there are few studies on the rheological properties of the high-viscosity asphalt with a surfactant warm mixing agent.

In this study, the influences of the dosage of surfactant WMA on physical properties and rheological properties of HVA which was modified by a self-developed SPR modifier were characterized.

\section{Materials and Measurement}

2.1. Materials. The AH-70 asphalts purchased from PetroChina Company Limited (Qinhuangdao, Hebei Province, China) were taken as the base asphalts. The physical properties and four-component compositions of the base asphalts are summarised in Table 1 . The self-developed $\mathrm{SBS} \mathrm{C}_{9}$ petroleum resin blends (SPR) were chosen as the modifier. The SPR modifier was prepared via a simple one-pot polymer alloying process by taking SBS and $\mathrm{C}_{9}$ petroleum resin as main raw materials (see preparation process in Supplementary Section). In addition, the molecular weight of SPR is 211114 and its melting point is $111.40^{\circ} \mathrm{C}$. The Evotherm M1 developed by MeadWestvaco Investment Co., Ltd. (China) was used as the surfactant WMA. The density of Evotherm M1is $0.95 \mathrm{~g} / \mathrm{cm}^{3}$ at $20^{\circ} \mathrm{C}$, and the kinematic viscosity is $960 \mathrm{mPas}$ at $25^{\circ} \mathrm{C}$. Furthermore, based on our previous researches, when the content of Evotherm M1 is $1.0 \mathrm{wt} \%$, the mixing temperature of high-viscosity asphalt mixture decreases by about $30^{\circ} \mathrm{C}$ if it is to meet the volume requirement.

2.2. Preparation of Samples. Based on the results of our previous researches on the high-viscosity asphalt and warm-mix asphalt, by using a stirrer with a temperature-control electric jacket, the warm-mix HVA (WHVA) was prepared, and the preparation process of warm-mix HVA is shown in Figure 1. To minimise the influence of other factors, the preparation technology is optimised according to previous research, and the temperature variation was no greater than $1^{\circ} \mathrm{C}$ during its preparation. The molten asphalt was poured into a cylindrical vessel after being weighed, and then the vessel was heated in the electric jacket. In this case, the asphalts were heated to $175^{\circ} \mathrm{C}$ while stirring at $300 \mathrm{rpm}$, to which the SPR modifier was slowly added. After the stirring rate was adjusted to $800 \mathrm{rpm}$, the asphalts were stirred for $2.5 \mathrm{~h}$. Thereafter, WMA was slowly added to the asphalts and stirred the mixture for $0.5 \mathrm{~h}$ to obtain warm-mix HVA. For comparison, the prepared warm-mix HVA in which the dosage of WMA accounts for $0 \mathrm{wt} \%$ (no added WMA), $0.5 \mathrm{wt} \%, 1.0 \mathrm{wt} \%, 1.5 \mathrm{wt} \%$, and $2.0 \mathrm{wt} \%$ of HVA were separately numbered: WHVA0, WHVA0.5, WHVA1.0, WHVA1.5, and WHVA2.0, respectively.

2.3. Physical Properties Test. Conventional tests were carried out to evaluate the properties of warm-mix HVA, including penetration (ASTM D5), softening point (ASTM D36), ductility (ASTM D113), kinematic viscosity (ASTM D4402), motive viscosity $\left(60^{\circ} \mathrm{C}\right)$ (ASTM D4402), and elastic recovery (ASTM D6084). 
TABle 1: Physical properties and chemical compositions of AH-70 asphalt.

\begin{tabular}{lcc}
\hline Properties & Specifications & $\begin{array}{c}\text { Measured } \\
\text { values }\end{array}$ \\
\hline Penetration $\left(25^{\circ} \mathrm{C}, 0.1 \mathrm{~mm}\right)$ & ASTM D5 \\
Penetration index $(\mathrm{PI})$ & ASTM D5 & -1 \\
Softening point $\left(\mathrm{R} \& \mathrm{~B},{ }^{\circ} \mathrm{C}\right)$ & ASTM D36 & 48.5 \\
Ductility $\left(15^{\circ} \mathrm{C}, \mathrm{cm}\right)$ & ASTM D113 & 168 \\
Kinematic viscosity $\left(135^{\circ} \mathrm{C}, \mathrm{Pa} \cdot \mathrm{s}\right)$ & ASTM D4402 & 0.475 \\
Density $\left(15^{\circ} \mathrm{C}, \mathrm{g} \cdot \mathrm{cm}^{-3}\right)$ & ASTM D70 & 1.014 \\
\hline Saturates $(\mathrm{wt} \%)$ & & 16.29 \\
Aromatics $(/ \mathrm{wt} \%)$ & ASTM D4124 \\
Resins $(\mathrm{wt} \%)$ & & 39.68 \\
Asphaltenes $(\mathrm{wt} \%)$ & & 30.68 \\
\hline
\end{tabular}

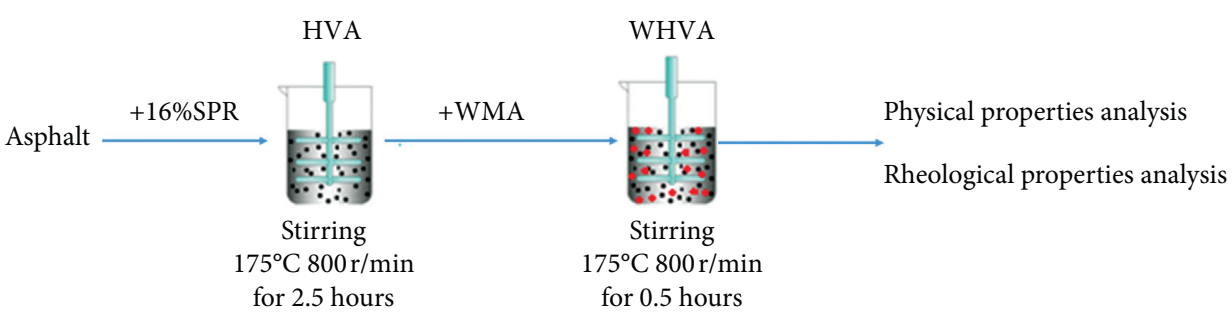

Figure 1: Preparation process of warm-mix HVA.

2.4. Rheological Test. By applying a MCR302 DSR rheometer (Anton Paar), the rheological behaviours of the warm-mix high-viscosity asphalt were explored. Strain and stress sweep tests were previously employed on each sample to obtain the linear viscoelastic range. Within the linear viscoelastic range, the samples were subjected to small-amplitude oscillatory shear testing to acquire the isothermal sweep results at frequencies of 0.1 to 50 rads at $5^{\circ} \mathrm{C}, 25^{\circ} \mathrm{C}, 40^{\circ} \mathrm{C}, 55^{\circ} \mathrm{C}$, and $75^{\circ} \mathrm{C}$. In the temperature sweep test, the strain control mode was adopted, the frequency was at $10 \mathrm{rad} / \mathrm{s}$, and the temperature was incrementally increased (by $10^{\circ} \mathrm{C}$ steps) from $30^{\circ} \mathrm{C}$ to $120^{\circ} \mathrm{C}$. It is worth noting that a $25 \mathrm{~mm}$ diameter plateplate geometry with a $1 \mathrm{~mm}$ gap was used for measurements at room temperature $\left(20^{\circ} \mathrm{C}\right)$ or above, while an $8 \mathrm{~mm}$ diameter plate-plate geometry with a $2 \mathrm{~mm}$ gap was applied for tests below the room temperature. In the multistress creep recovery (MSCR) test, 10 cycles were applied, each of which consisted of $1 \mathrm{~s}$ of creep and $9 \mathrm{~s}$ of recovery. The two processes were separately conducted at $0.1,1.6$, and $3.2 \mathrm{kPa}$. Moreover, a steady-state viscous flow test was conducted on the samples under the steady-state shear mode of the rheometer, with a $25 \mathrm{~mm}$ diameter plate-plate geometry with a $1 \mathrm{~mm}$ gap. The viscous flow properties of the samples were measured within a large range $\left(10^{-3}\right.$ to $\left.10^{1} \mathrm{~s}^{-1}\right)$ of shear rates at $60^{\circ} \mathrm{C}$. The creep behaviours of the high-viscosity asphalt at a low temperature were characterized by applying a bending beam rheometer (BBR) to attain two indices, creep stiffness $S$ and the rate of change $m$ of the stiffness with time [23].

By using the time-temperature equivalence principle, the viscoelasticity within wide frequency and temperature ranges was acquired. However, the viscoelasticity spanning several orders of magnitude was rarely measured directly.
The time-temperature equivalence principle indicates that the influence of prolonging the test duration (or decreasing the frequency) on mechanical properties of materials is equivalent to that of increasing the temperature. According to the time-temperature equivalence principle, various viscoelastic parameters measured through experiment can be superimposed through shift factors to draw a master curve.

\section{Results and Discussion}

3.1. Physical Properties. The effects of WMA on physical properties of warm-mix HVA are shown in Figure 2. The penetration, softening point, ductility, elastic recovery, and viscosity indices reflecting physical properties separately can reflect high- and low-temperature performance, mechanical properties, and workability of asphalts. As shown in Figure 2, with increasing dosage of WMA, the physical properties of warm-mix HVA generally show the following changes: rising penetration, decreasing softening point, growing ductility, reducing Brookfield viscosity at $135^{\circ} \mathrm{C}$ and dynamic viscosity at $60^{\circ} \mathrm{C}$, and an insignificantly changing elastic recovery. This indicated that the addition of WMA can lower the viscosity of warm-mix HVA and therefore improve its workability.

The warm-mix asphalt technology based on WMA is expected to reduce the viscosity (high-temperature viscosity) of asphalts during construction through addition of WMA while showing an insignificant influence on the low-temperature viscosity and rutting resistance. Therefore, it is important to determine an appropriate dosage of WMA for warm-mix HVA. Through measuring different effects of the 


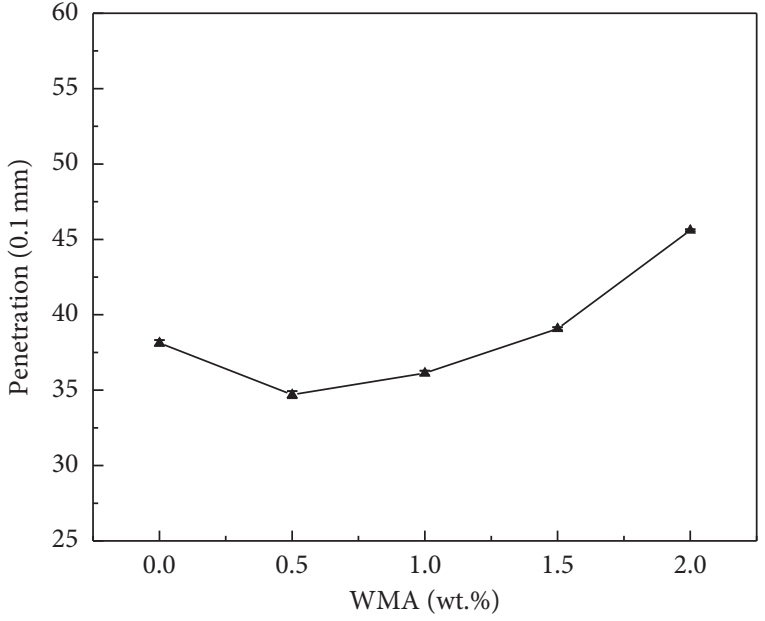

(a)

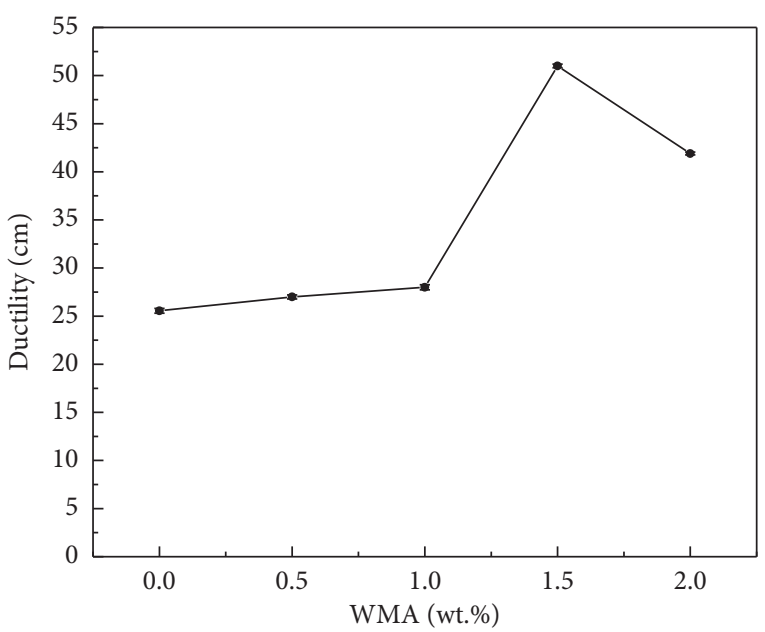

(c)

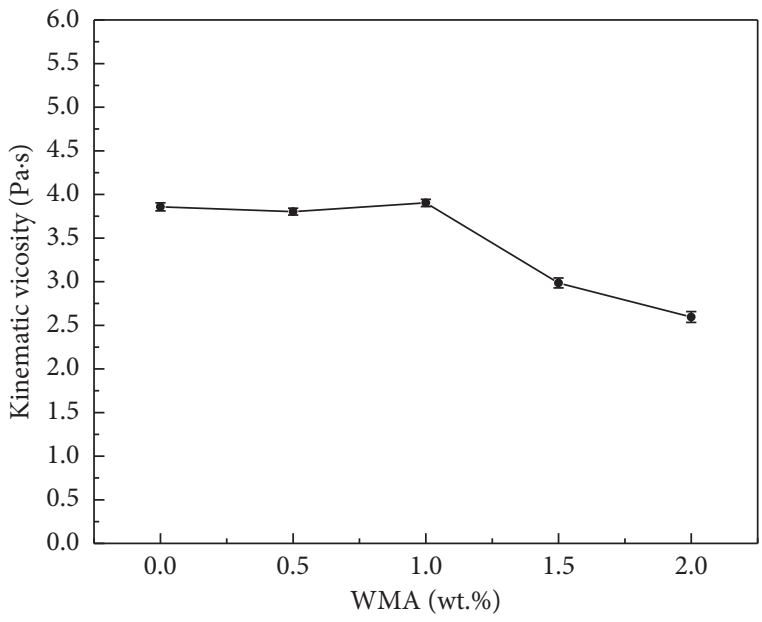

(e)

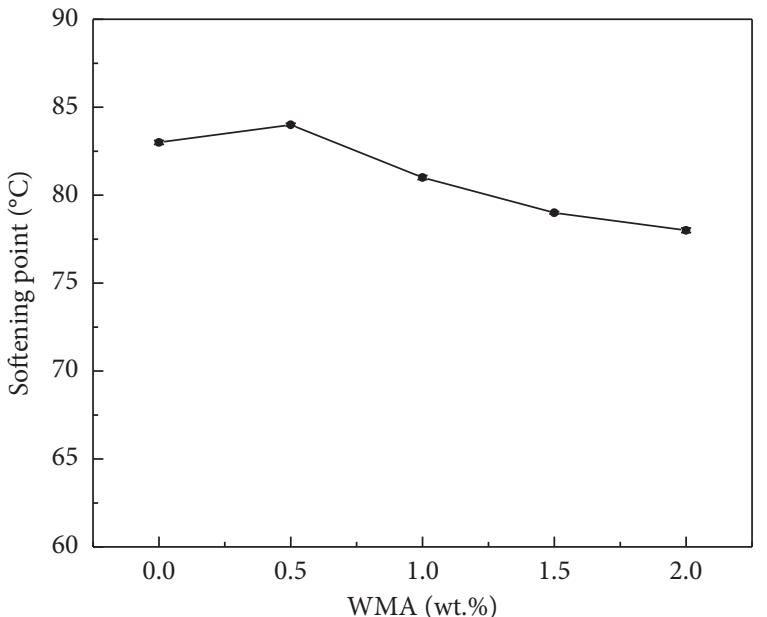

(b)

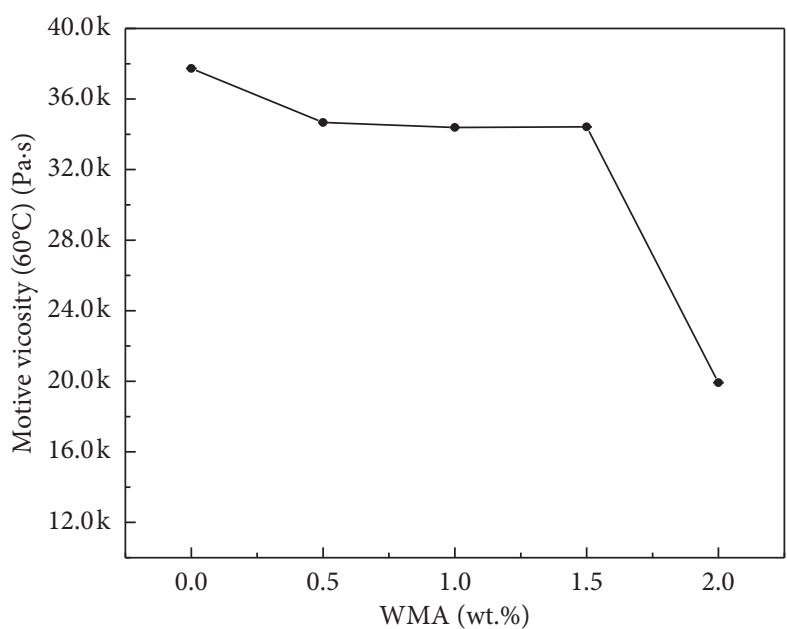

(d)

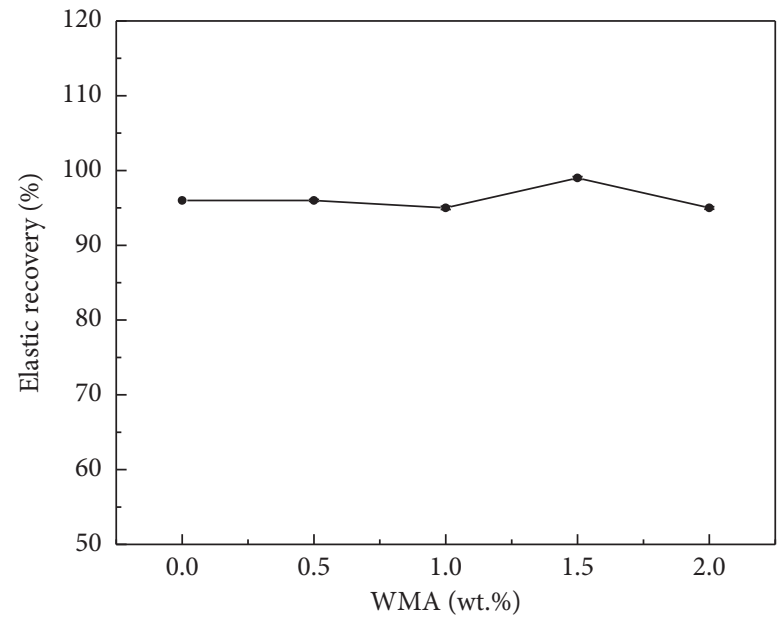

(f)

Figure 2: Physical properties of warm-mix HVA: (a) penetration; (b) softening point; (c) ductility; (d) motive viscosity $\left(60^{\circ} \mathrm{C}\right)$; (e) kinematic viscosity $\left(135^{\circ} \mathrm{C}\right)$; (f) elastic recovery.

dosage of WMA on physical properties of the warm-mix HVA, it can be seen that the appropriate dosage of WMA was between 0.5 and $1.5 \mathrm{wt} \%$.
3.2. Rheological Properties. The utilisation of the porous asphalt pavement depends on the mechanical and viscoelastic properties of HVA. The linear viscoelasticity of warm- 
mix HVA is sensitive to changes in composition and structure of the polymers and dosage of WMA. Due to the complexity of the systems, it is difficult to deduce the characteristics of the internal structures of warm-mix HVA. The rheological parameters within the linear viscoelastic range were independent of changing stress and strain while were only related to the material properties. Therefore, the linear viscoelasticity of asphalts was sensitive to changes in the internal structures of modified asphalts. Testing the linear viscoelasticity is a powerful way of investigating the effects of different structures of polymers and the dosages of WMA on performances of warm-mix HVA. In this section, through a frequency sweep, temperature sweep, steady-state shear testing, MSCR testing, and low-temperature creep testing, the rheological properties of warm-mix HVA were measured.

\subsubsection{Frequency Sweep at Intermediate and High} Temperatures. The master curves of warm-mix HVA at $25^{\circ} \mathrm{C}$ at different dosages of WMA are shown in Figure 3. The master curves are obtained through the shift in frequencysweep curves at $5^{\circ} \mathrm{C}, 25^{\circ} \mathrm{C}, 40^{\circ} \mathrm{C}, 55^{\circ} \mathrm{C}$, and $70^{\circ} \mathrm{C}$. As shown in Figure 3 , the dosage of WMA exerted complex effects on the complex modulus $G^{*}$ of warm-mix HVA. Over the whole frequency range, there was a significant difference in the master curves of warm-mix HVA with different dosages of WMA. In a low $\omega$ range, the addition of WMA caused the value of $G^{*}$ warm-mix HVA to increase and then decrease. It reached a maximum at a dosage of WMA of $1.0 \mathrm{wt} \%$. Adding less than $1.0 \mathrm{wt} \%$ WMA can improve the high-temperature performance of warm-mix HVA while excessive amount of WMA will destroy the high-temperature performance and rutting resistance of warm-mix HVA.

As shown in the master curves in Figure 3(a), the timetemperature equivalence principle can be applied to a warmmix HVA. The change of shift factors with temperature is shown in Figure 3(b). It can be seen that the warm-mix HVA with different dosages of WMA exhibited different shift factors at different temperatures. The temperature dependence of the shift factor can characterise the temperature susceptibility of samples. The dependence of shift factors on temperature can be described by utilising an Arrhenius-like equation or Williams-Landel-Ferry (WLF) equation [24]. Here, we applied the Arrhenius-like equation to describe the change of shift factors with temperature.

It can be seen from Figure 4(a), although warm-mix HVA with different dosages of WMA showed approximate shift factors, the difference in shift factors can be quantitatively distinguished according to the slope of the Arrhenius-like equation. That is, the activation energy $E_{\mathrm{a}}$ was used to characterise the systems, as shown in Figure 4(b).

Figure 4(b) shows that the addition of WMA reduced the activation energy of the warm-mix HVA, indicating that the sensitivity of the warm-mix HVA to temperature decreased. Moreover, with the increase of WMA, the activation energy of the warm-mix HVA first decreased and then stabilised. This is because the change of activation energy is mainly determined by SPR modifier molecules. The hydrophilic segment of Evotherm M1 is composed of long-chain aliphatic alkanes. Furthermore, the aliphatic alkanes can be adsorbed by SPR modifier molecules to promote their swelling and dispersion in asphalt and then play a better role in modification. However, when the amount of WMA reaches a certain value, the adsorption reaches equilibrium and the activation energy tends to equilibrium as well.

3.2.2. Temperature Sweeps. Apart from the master curve, the samples were subjected to temperature sweep within a large temperature range to explore the linear viscoelasticity of warm-mix HVM asphalts. The changes in storage modulus $G^{\prime}$, loss modulus $G^{\prime \prime}$, and rutting factor $G^{*} / \sin \delta$ with temperature are shown in Figure 5. With increasing temperature, the values of $G^{\prime}$ and $G^{\prime \prime}$ of the warm-mix HVA decreased and presented complex changes with temperature as well. Within the medium- and high-temperature range $\left(30^{\circ} \mathrm{C}\right.$ to $\left.70^{\circ} \mathrm{C}\right)$, the values of $G^{\prime}$ and $G^{\prime \prime}$ of various samples were similar and showed a consistent rate of change with temperature. Above $80^{\circ} \mathrm{C}$, especially in the ultrahigh-temperature range (above $100^{\circ} \mathrm{C}$ ), $G^{\prime}$ and $G^{\prime \prime}$ differed significantly. The relative values of $G^{\prime}$ and $G^{\prime \prime}$ of various samples, in descending order, were WHVA1.0, WHVA0.5, WHVA1.5, WHVA0, and WHVA2.0. Considering the rate of change, WHVA2.0 showed the largest rate of reduction with increasing temperature, followed by WHVA0. It is worth noting that WHVA1.0, WHVA0.5, and WHVA1.5 exhibited similar rates of change: within the temperature range of $90^{\circ} \mathrm{C}$ to $100^{\circ} \mathrm{C}, G^{\prime} \sim T$ and $G^{\prime \prime} \sim T$ curves of the samples both showed a zone of low gradient. In that case, the slope of the curves was at a minimum. When the temperature was higher than $100^{\circ} \mathrm{C}, G^{\prime}$ and $G^{\prime \prime}$ decreased significantly.

AASHTO code M320 defines the rutting factor $G^{*} / \sin \delta$ to characterise the rutting resistance of asphalts and requires that $G^{*} / \sin \delta$ of new asphalts be no lower than $1.0 \mathrm{kPa}$. The changes in rutting factor $G^{*} / \sin \delta$ with temperature are shown in Figure 5(c): $G^{*} / \sin \delta$ decreased with increasing temperature, and these were consistent with the change of $G^{\prime}$ and $G^{\prime \prime}$ The changes in failure temperature when various samples showed rutting with WMA are shown in Figure 5(d), the failure temperature of warm-mix HVA increased at first and then decreased with increasing dosage of WMA, and it reached a maximum when the dosage of WMA was $1.5 \mathrm{wt} \%$.

As described above, at low content, WMA can promote the dispersion of modifiers in asphalt and play a better role in modification. However, due to the low viscosity of WMA, when the content of WMA exceeds a certain value, the viscosity and rutting resistance of warm-mix HVA will decrease.

3.2.3. Flow Behaviour. The linear viscoelasticity was obtained under a small-amplitude deformation. Nonlinear viscoelasticity measured under a large-amplitude deformation can reveal useful information, especially that distinguishing differences in modified asphalts caused by changes to polymer structures and that establishing relationships between structure and performance. 


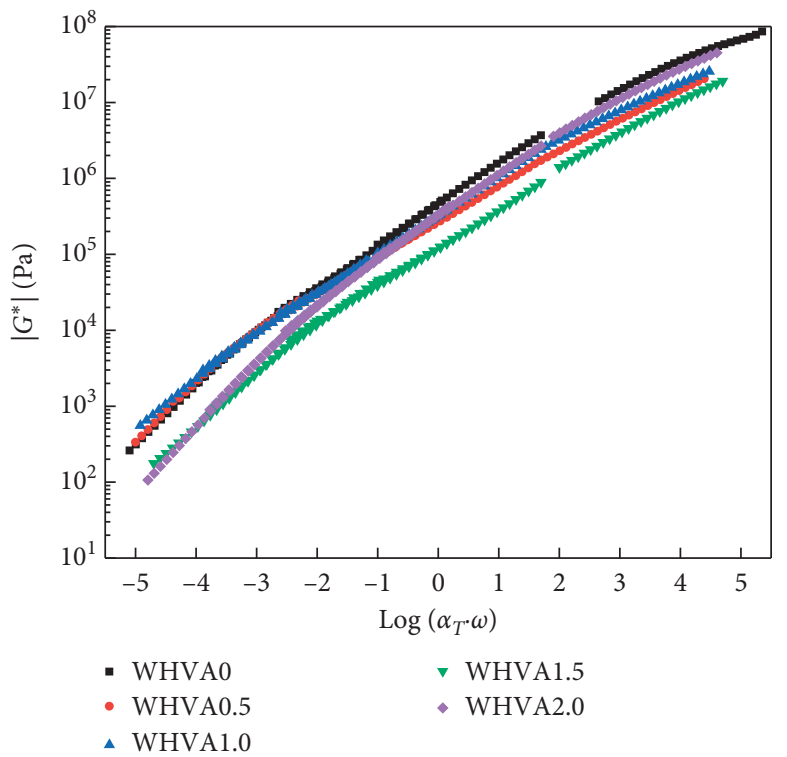

(a)

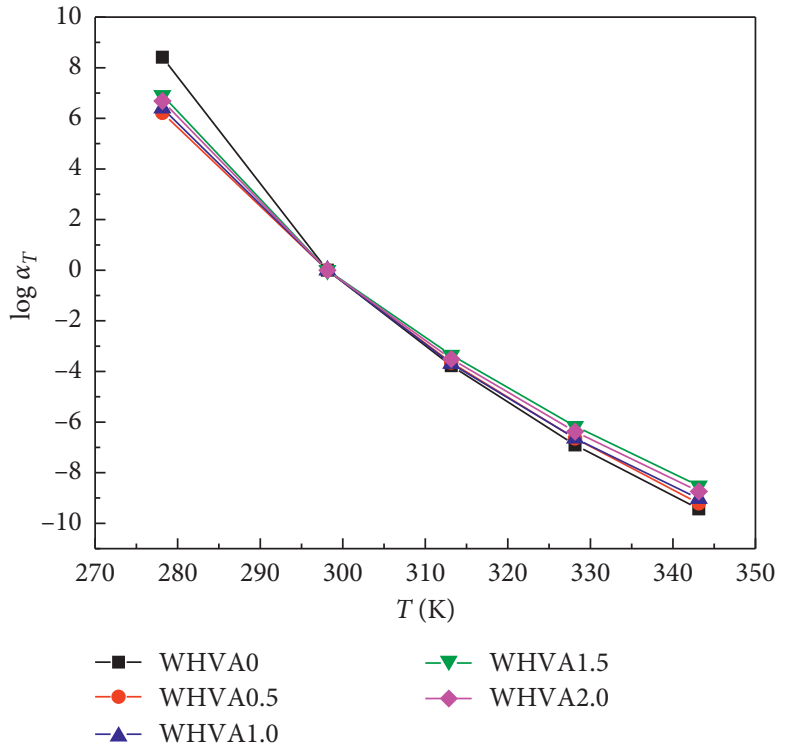

(b)

Figure 3: (a) Master curves and (b) shift factors at different temperatures for warm-mix HVA.

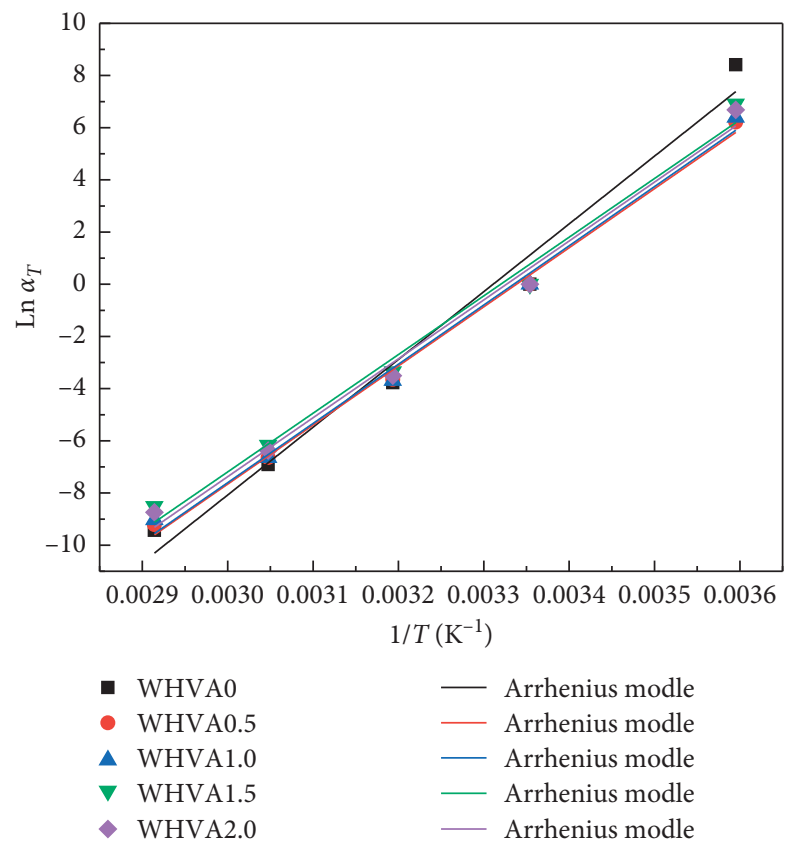

(a)

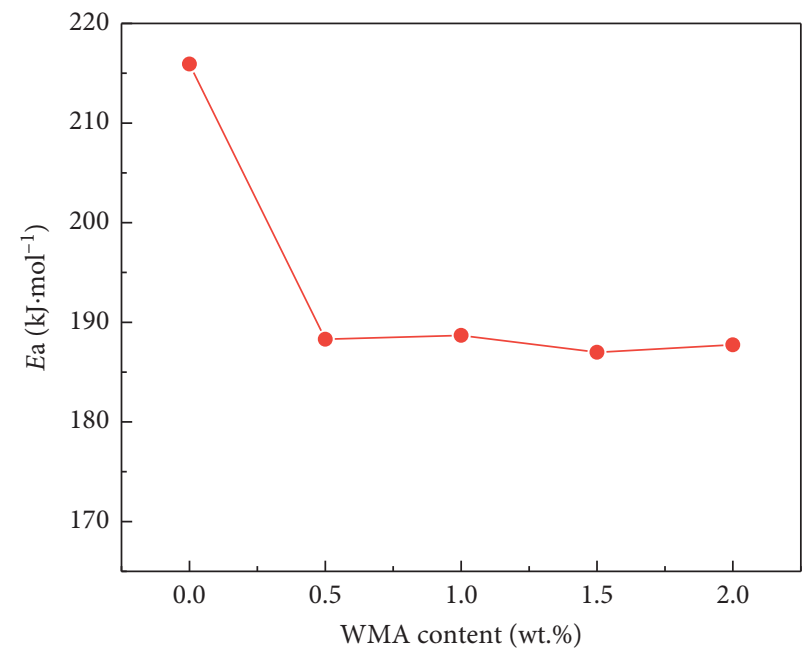

(b)

FIGURE 4: (a) Evolutions of shift factors versus temperature and (b) variations of activation energy as a function of WMA contents for warmmix asphalt.

The change in steady-state viscosity of warm-mix HVA at $60^{\circ} \mathrm{C}$ with shear rate (that is, the viscous flow curve) is shown in Figure 6. Within the whole range of shear rates tested, the viscosity of the warm-mix HVA decreased slightly with increasing shear rate, showing shear thinning behaviour. The viscous flow curve can be fitted by applying the Cross model [24], and the fitting parameters of warm-mix HVA obtained by using the Cross model are listed in Table 2.
As shown in Table $2, \eta_{0}, \eta_{\infty}, \lambda$, and $d$ denote the zeroshear viscosity (ZSV), the viscosity corresponding to an infinite shear rate, the characteristic time, and flow index, respectively. The value of $\eta_{0}$ of warm-mix HVA increased at first and then decreased with increasing dosage of WMA. When the dosage of WMA was $1.0 \mathrm{wt} \%, \eta_{0}$ of warm-mix HVA was maximised. For warm-mix HVA, within the dosage range of WMA tested in the study, the addition of 

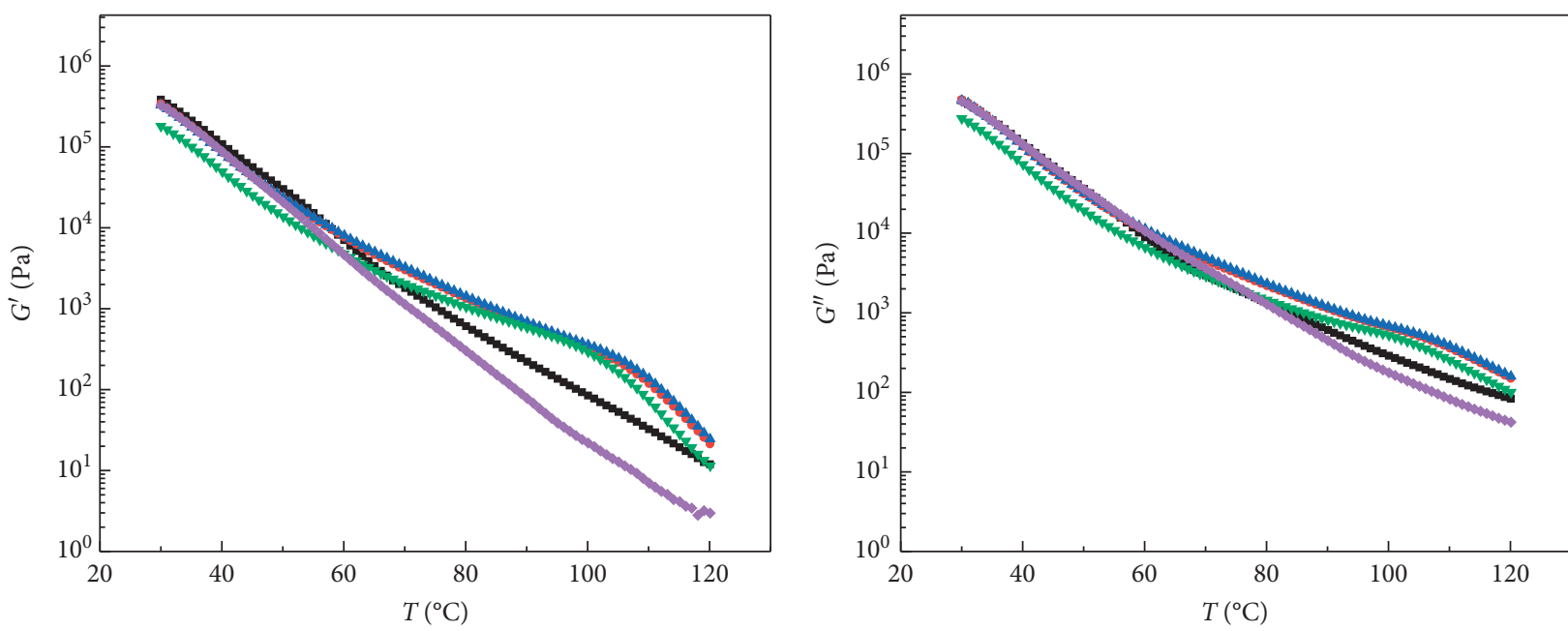

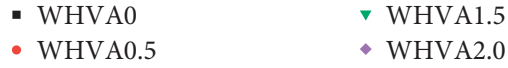

- WHVA1.0

(a)

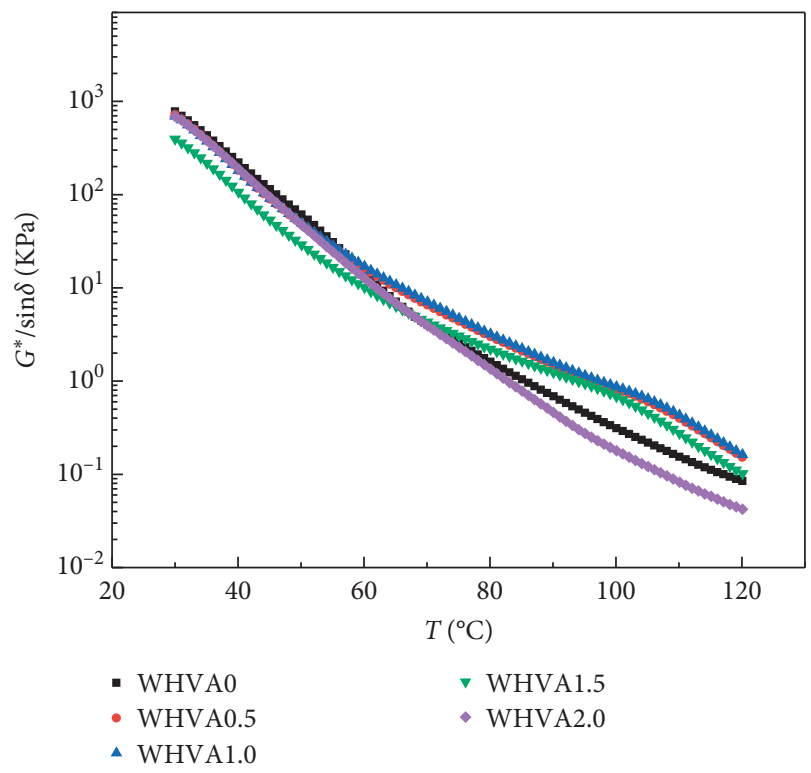

(c)

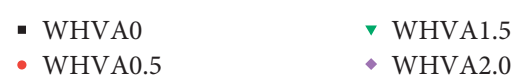

A WHVA1.0

(b)

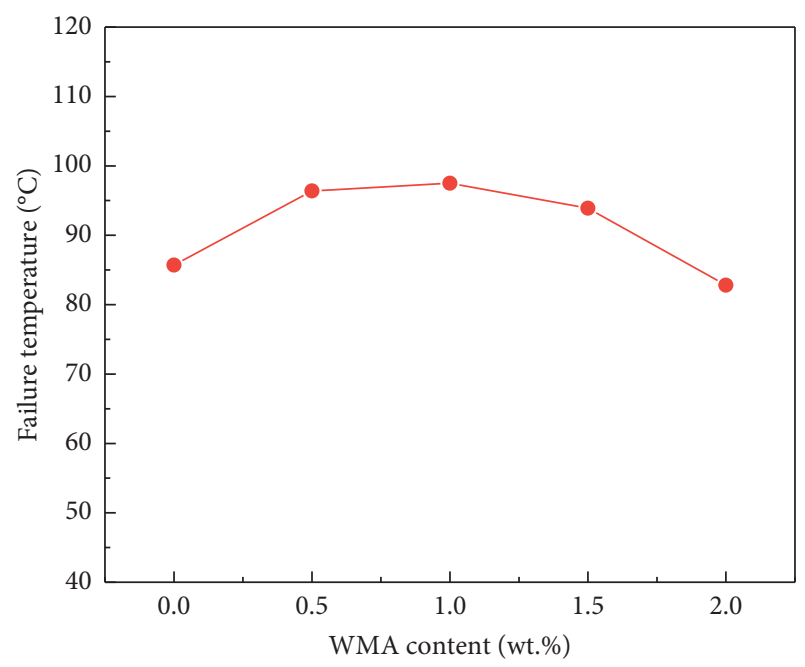

(d)

Figure 5: Evolution of (a) $G^{\prime}$, (b) $G^{\prime \prime}$, and (c) $G^{*} / \sin \delta$ versus temperature and (d) temperature calculated at the point of $G^{*} / \sin \delta=1.0 \mathrm{kPa}$ for warm-mix HVA.

WMA increased the ZSV $\left(\eta_{0}\right)$ of HVA. The reason for this result is consistent with that in Section 3.2.4.

3.2.4. MSCR. MSCR is an index developed in recent years to evaluate high-temperature performance of modified asphalts. In this study, MSCR was conducted at $60^{\circ} \mathrm{C}$ under three stress levels $(100,1600$, and $3200 \mathrm{~Pa})$. Through MSCR, two parameters (involving recovery rate $R$ and nonrecoverable compliance $J_{\mathrm{nr}}$ ) can be acquired. $R$ and $J_{\mathrm{nr}}$ were separately calculated based on recoverable and nonrecoverable strains. The strain responses of warm-mix HVA within ten cycles at $60^{\circ} \mathrm{C}$ under $100 \mathrm{~Pa}$ are shown in Figure 7.
When the dosage of WMA was between 0 and $1.0 \mathrm{wt} \%$, the higher the strain on warm-mix HVA when the creep stage ended, the higher the strain when the recovery stage was completed in a creep-recovery cycle. The strain decreased with increasing dosage of WMA; however, the strains on WHVA1.5 and WHVA2.0 samples were much greater than those on the other samples.

To characterise the effects of WMA on high-temperature performances of warm-mix HVM asphalts, Figure 8 shows the changes of recovery rate of warm-mix HVA with dosage of WMA at $40^{\circ} \mathrm{C}$ and $60^{\circ} \mathrm{C}$ under three stresses. It can be seen from Figure $8(\mathrm{a})$ that, at $40^{\circ} \mathrm{C}$, with increasing dosage of WMA, the recovery rate of warm-mix HVA increased at 


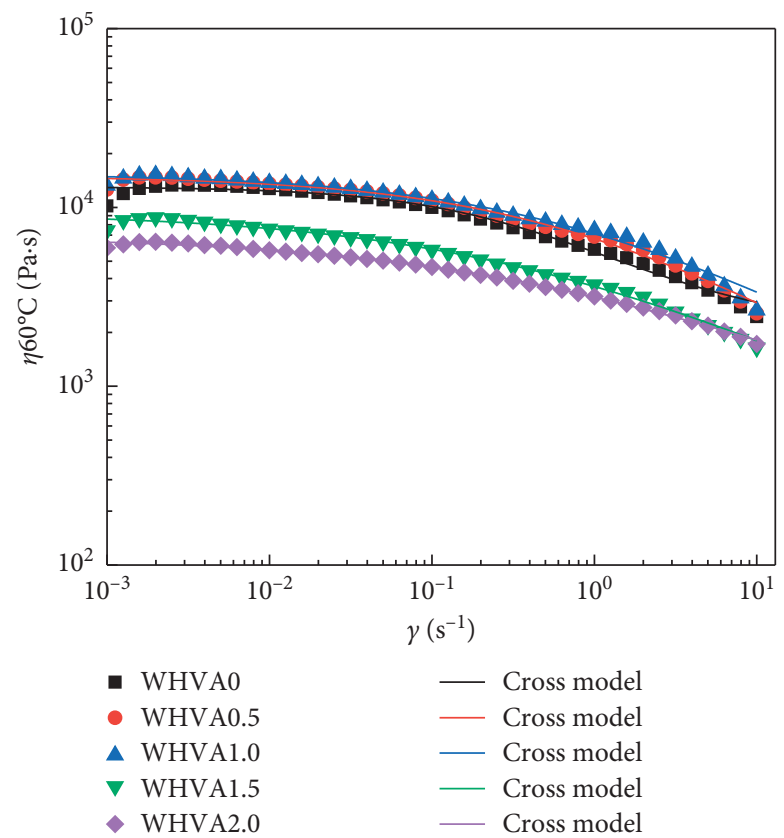

Figure 6: Flow curves of warm-mix HVA at $60^{\circ} \mathrm{C}$ as a function of WMA content.

TABle 2: The resulting Cross model parameters as a function of WMA content for warm-mix HVA.

\begin{tabular}{ccccccc}
\hline & \multicolumn{5}{c}{ Various WMA contents (wt.\%) } \\
& & 0 & 0.5 & 1.0 & 1.5 & 2.0 \\
\hline \multirow{3}{*}{ HVA } & $\eta_{0}(\mathrm{~Pa} \cdot \mathrm{s})$ & 13034 & 15021 & 15434 & 5332 \\
& $\eta_{\infty}(\mathrm{Pa} \cdot \mathrm{s})$ & 2118 & 1.252 & $3.3561 E-82$ & $3.784 E-30$ & 300.242 \\
& $\lambda(\mathrm{s})$ & 2.679 & 1.536 & 1.362 & 2.960 & 1.896 \\
& $D$ & 0.759 & 0.520 & 0.490 & 0.423 \\
\hline
\end{tabular}

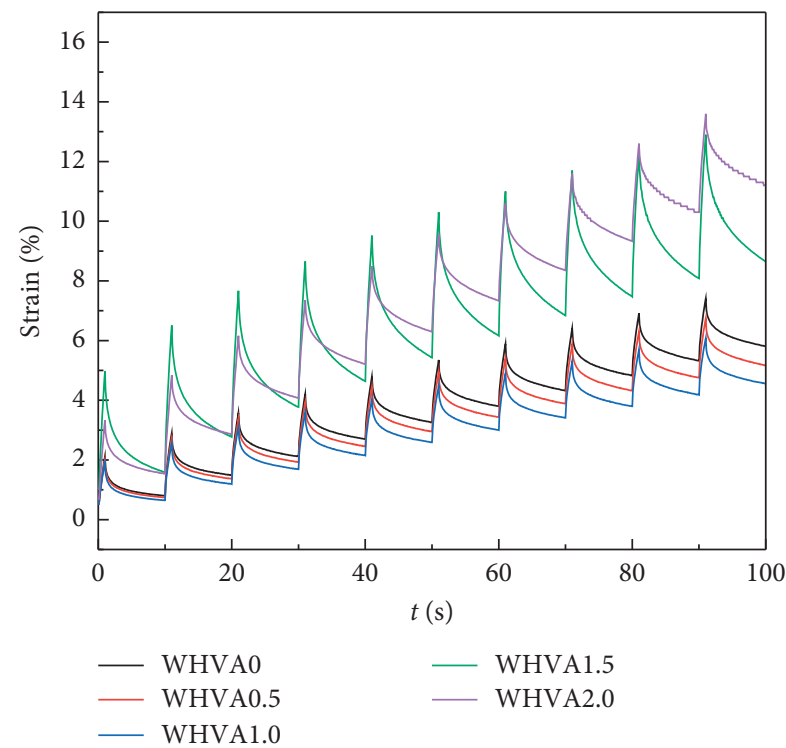

FIGURE 7: Strain response in the MSCR test (ten cycles) for warmmix HVA at $60^{\circ} \mathrm{C}$ and $100 \mathrm{~Pa}$.

first, then decreased, and finally slightly increased, and it reached its maximum and minimum at dosages of WMA of $0.5 \mathrm{wt} \%$ and $1.5 \mathrm{wt} \%$, respectively. At $60^{\circ} \mathrm{C}$, with increasing dosage of WMA, the recovery rate of warm-mix HVA increased at first, then decreased, and finally increased slightly, and its maximum appeared at $1.5 \mathrm{wt} \%$ dosage of WMA, indicating that the recoverability of the asphalt pavement was the strongest. Additionally, increasing temperature and stress also resulted in the significant reduction of $R$ of warmmix HVA samples.

The change in nonrecoverable compliance $J_{\mathrm{nr}}$ with dosage of WMA is shown in Figure 8(b): $J_{\mathrm{nr}}$ increased with increasing temperature. The difference between $J_{\mathrm{nr}} 100$ and $J_{\mathrm{nr}} 3200$ increased with increasing dosage of WMA. At $40^{\circ} \mathrm{C}$, the $J_{\mathrm{nr}}$ of warm-mix HVA increased and then decreased with increasing dosage of WMA, and its maximum was found when the dosage of WMA was $1.5 \mathrm{wt} \%$. At $60^{\circ} \mathrm{C}, J_{\mathrm{nr}}$ first decreased, then increased with increasing dosage of WMA, and was minimised when the dosage of WMA was $1.0 \mathrm{wt} \%$.

3.2.5. Low-Temperature Creep Behaviour. To characterise the influence of the dosage of WMA on low-temperature creep behaviour in warm-mix HVA, the creep behaviours of warm-mix HVA under different loading durations at $-18^{\circ} \mathrm{C}$ and $-24^{\circ} \mathrm{C}$ were tested in the BBR. The changes in creep stiffness $S$ and $m$ with loading time are shown in Figure 9. Ductility of the system decreased. When the dosage of WMA was $1.5 \mathrm{wt} \%$, minimum $s$ and maximum $m$ were found 


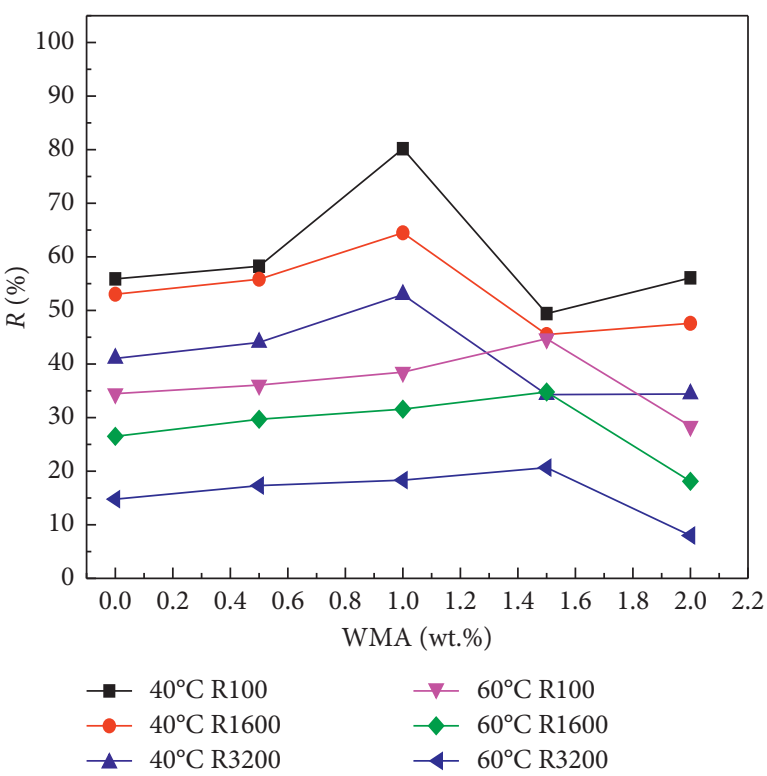

(a)

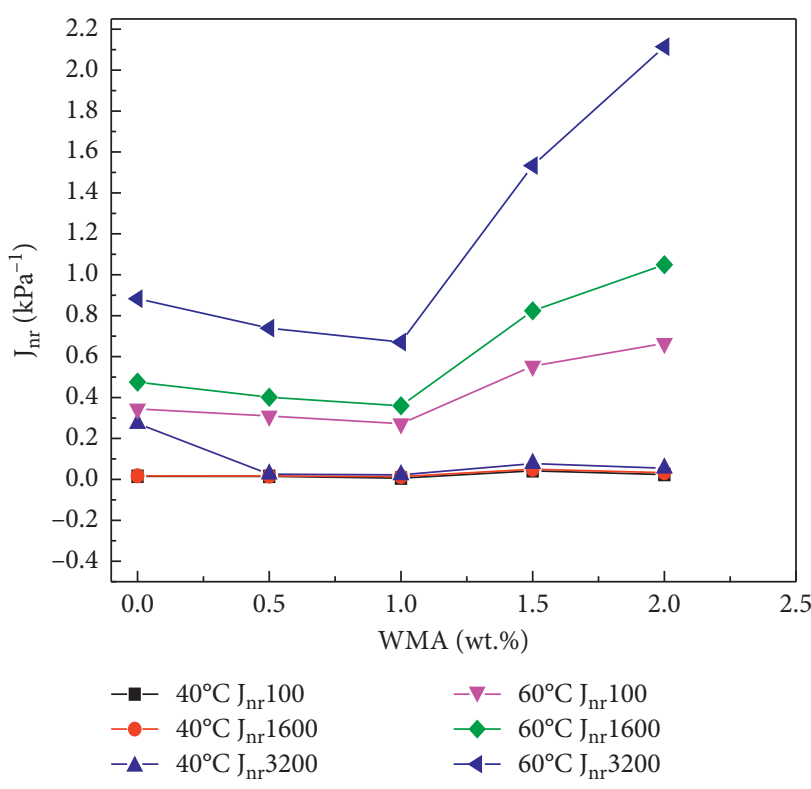

(b)

Figure 8: (a) The percent recovery and (b) nonrecoverable creep compliance calculated from the MSCR test at $40^{\circ} \mathrm{C}$ and $60^{\circ} \mathrm{C}$ and three stress levels for warm-mix HVA.

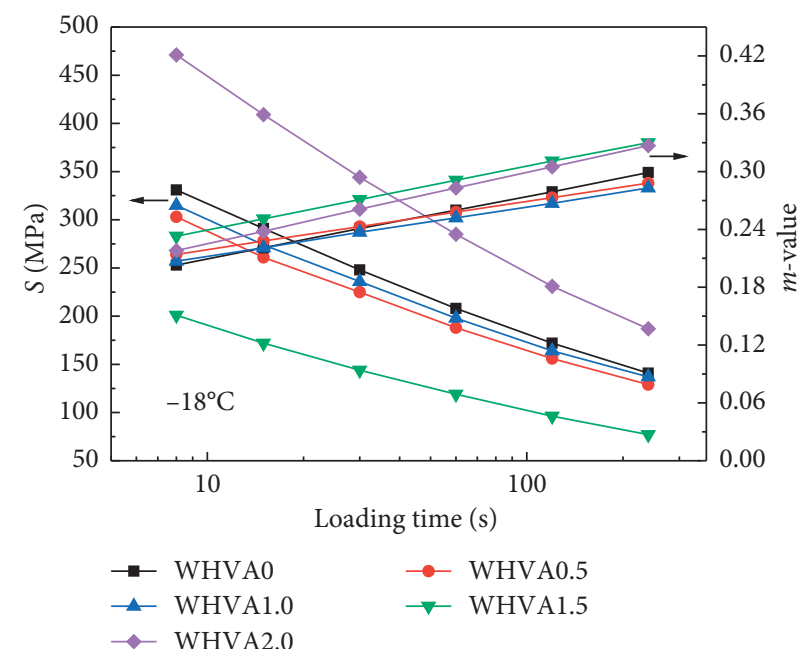

(a)

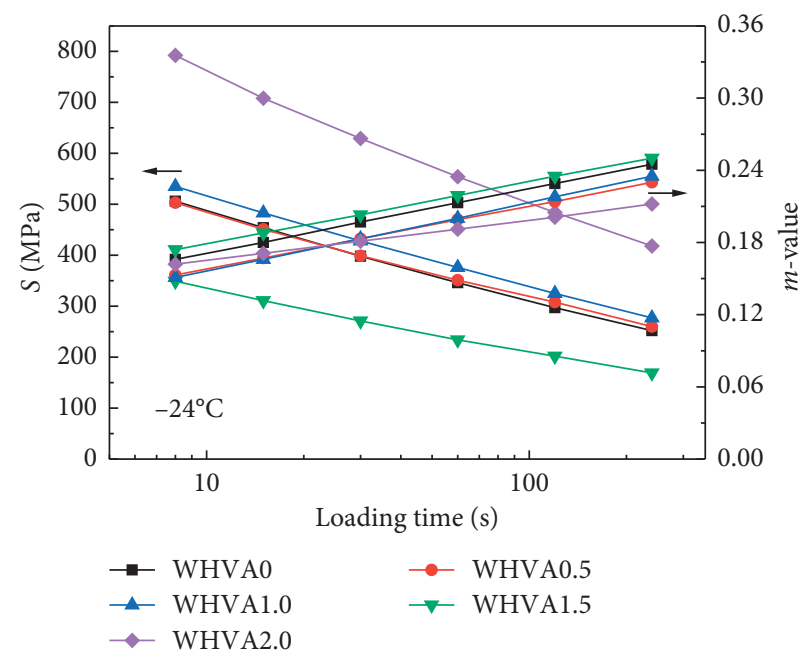

(b)

FIgURE 9: Continued. 


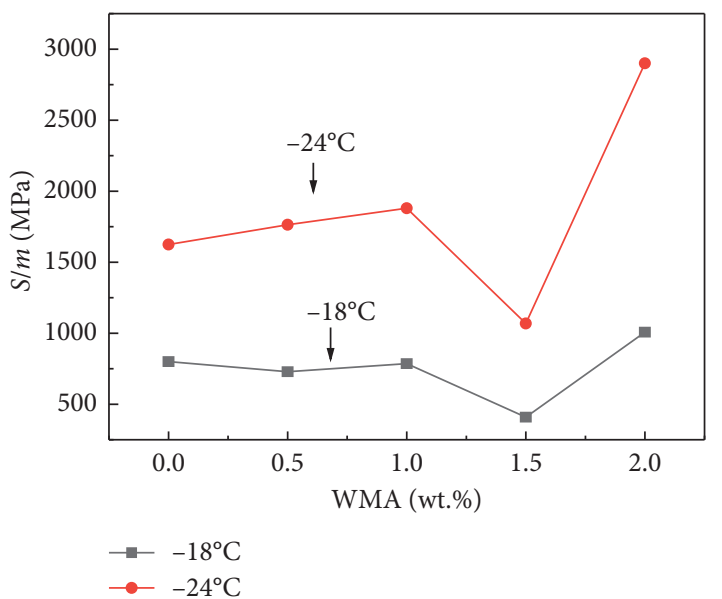

(c)

Figure 9: Evolution of $S$ and $m$ values versus loading time for warm-mix $\mathrm{HVA}$ at (a) $-18^{\circ} \mathrm{C}$ and (b) $-24^{\circ} \mathrm{C}$, and (c) the ratio of creep stiffness $S$ and $m$ as a function of WMA content at -18 and $-24^{\circ} \mathrm{C}$.

similar to that at $-18^{\circ} \mathrm{C}$. As for a warm-mix $\mathrm{HVA}$, at $-18^{\circ} \mathrm{C}$, the $S$ of WHVA1.5 was minimised; however, the $S$ of WHVA2.0 was maximised. WHVA1.5 exhibited the largest $m$. At $-24^{\circ} \mathrm{C}, S$ and $m$ of warm-mix HVA showed a similar trend to those at $-8^{\circ} \mathrm{C}$. This implied an optimal low-temperature performance of the warm-mix HVA system at a dosage of WMA of $1.5 \mathrm{wt} \%$.

At low temperature, a low $S$ and a high $m$ represent a strong cracking resistance of the asphalts. The coefficient $I$ was defined to characterise the low-temperature cracking resistance of asphalts, that is, the ratio of $S$ to $m$ at $60 \mathrm{~s}$. The lower the value of $I$, the better the low-temperature performance. At $-18^{\circ} \mathrm{C}$ and $-24^{\circ} \mathrm{C}$, the changes in $S / m$ values of warm-mix HVA with changing dosage of WMA are shown in Figure 9(c): the $S / m$ values of the warm-mix HVA decreased at first and then rose with increasing dosage of WMA. I was minimised when the dosage of WMA was $1.5 \mathrm{wt} \%$. With increasing dosage of WMA, the value of $I$ increased; therefore, for warm-mix HVA, the most suitable dosage of WMA was $1.5 \mathrm{wt} \%$ from the perspective of lowtemperature performance.

\section{Conclusion}

The effects of surfactant WMA on physical and rheological properties of HVA prepared with the self-developed SPR modifier were measured. The addition of WMA can decrease the viscosity and improve the workability of HVA. With the increase of WMA content, penetration and ductility increased; softening point, kinematic viscosity at $135^{\circ} \mathrm{C}$, and motive viscosity at $60^{\circ} \mathrm{C}$ decreased; and elasticity recover was unchanged.

Meanwhile, with the increase of WMA content, the modulus, failure temperature, viscosity, and recovery rate of warm-mix HVA increased at first and then decreased, and the maximum value appeared at $1.0 \%-1.5 \%$. Moreover, when the amount of WMA is $1.5 \%$, the low-temperature performance of warm-mix HVA shows the best value. Thus, for HVA, in order to achieve ideal rheological properties, the recommended amount of WMA is $1.0 \%-1.5 \%$.

As a conclusion, WMA could be an alternative for increasing workability of HVA. However, the amount of a warm mixing agent must be reasonably determined because it has a great influence on high-low temperature performance of warm-mix HVA. Moreover, in the future research, we will pay more attention to the effect of WMA on the performance of high-viscosity asphalt mixture, especially the durability.

\section{Data Availability}

The data used to support the findings of this study are available from the corresponding author upon request.

\section{Conflicts of Interest}

The authors declare no conflicts of interest.

\section{Acknowledgments}

We would like to acknowledge many coworkers, students, and laboratory assistants for providing technical support on instrument analysis. Thanks are due to Dr. Edward C. Mignot, Shandong University, for linguistic advice. This work was financially supported by the National Natural Science Foundation of China (No. 51608511), Key R \& D Project of Shandong Province (2018GGX105013), and Project of Science and Technology Support for Youth Entrepreneurship in Colleges and Universities of Shandong Province (2019KJG004).

\section{Supplementary Materials}

It includes preparation method of the high-viscosity modifier SJH. (Supplementary Materials) 


\section{References}

[1] Y. Sun, Z. Gu, J. Wang, C. Fang, and X. Yuan, "Study on relaxation damage properties of high viscosity asphalt sand under uniaxial compression," Advances in Civil Engineering, vol. 2018, Article ID 1498480, 12 pages, 2018.

[2] L. Li, H. Geng, and Y. Sun, "Simplified viscosity evaluating method of high viscosity asphalt binders," Materials and Structures, vol. 48, no. 7, pp. 2147-2156, 2015.

[3] L.-T. Geng, Q. Xu, R.-B. Ren, L.-Z. Wang, X.-L. Yang, and X.-Y. Wang, "Performance research of high-viscosity asphalt mixture as deck-paving materials for steel bridges," Road Materials and Pavement Design, vol. 18, no. 1, pp. 208-220, 2017.

[4] A. Moriyoshi, T. Jin, T. Nakai, H. Ishikawa, K. Tokumitsu, and A. Kasahara, "Construction and pavement properties after seven years in porous asphalt with long life," Construction and Building Materials, vol. 50, pp. 401-413, 2014.

[5] Q. Liu and D. Cao, "Research on material composition and performance of porous asphalt pavement," Journal of Materials in Civil Engineering, vol. 21, no. 4, pp. 135-140, 2009.

[6] X. Y. Zheng, S. M. Easa, T. Ji, Z. L. Jiang, and A. O. Abd El Halim, "Influence of warm-mix additives on physical, rheological, and morphological properties of high-viscosity asphalt," Journal of Materials in Civil Engineering, vol. 31, no. 2, 12 pages, 2019.

[7] B. Xu, M. Li, S. Liu, J. Fang, R. Ding, and D. Cao, "Performance analysis of different type preventive maintenance materials for porous asphalt based on high viscosity modified asphalt," Construction and Building Materials, vol. 191, pp. 320-329, 2018.

[8] F. Zhang and C. Hu, "Preparation and properties of high viscosity modified asphalt," Polymer Composites, vol. 38, no. 5, pp. 936-946, 2017.

[9] F. Zhang, C. Hu, and W. Zhuang, "The research for lowtemperature rheological properties and structural characteristics of high-viscosity modified asphalt," Journal of Thermal Analysis and Calorimetry, vol. 131, no. 2, pp. 1025-1034, 2018.

[10] H. Wang, Z. You, J. Mills-Beale, and P. Hao, "Laboratory evaluation on high temperature viscosity and low temperature stiffness of asphalt binder with high percent scrap tire rubber," Construction and Building Materials, vol. 26, no. 1, pp. 583590, 2012.

[11] X. Qin, S. Zhu, X. He, and Y. Jiang, "High temperature properties of high viscosity asphalt based on rheological methods," Construction and Building Materials, vol. 186, pp. 476-483, 2018.

[12] S. Li, T. Shields, S. Noureldin, and Y. Jiang, "Field evaluation of surface friction performance of chip seals in Indiana," Transportation Research Record: Journal of the Transportation Research Board, vol. 2295, no. 1, pp. 11-18, 2012.

[13] A. Shenoy, "Model-fitting the master curves of the dynamic shear rheometer data to extract a rut-controlling term for asphalt pavements," Journal of Testing and Evaluation, vol. 30, no. 2, pp. 95-102, 2002.

[14] L. Qu, Y. Gao, H. Yao et al., "Preparation and performance analysis of high-viscosity and elastic recovery modified asphalt binder," Advances in Civil Engineering, vol. 2019, Article ID 6070685, 16 pages, 2019.

[15] F. Zhang and C. Hu, "The composition and ageing of highviscosity and elasticity asphalts," Polymer Composites, vol. 38, no. 11, pp. 2509-2517, 2017.

[16] J. Zhang, G. Liu, L. Xu, and J. Pei, "Effects of WMA additive on the rheological properties of asphalt binder and high temperature performance grade," Advances in Materials Science and Engineering, vol. 2015, Article ID 467891, 7 pages, 2015.

[17] H. Yu, Z. Zhu, Z. Leng et al., "Effect of mixing sequence on asphalt mixtures containing waste tire rubber and warm mix surfactants," Journal of Cleaner Production, vol. 246, Article ID 119008, 2020.

[18] J. Ouyang, J. Zhao, and Y. Tan, "Modeling mechanical properties of cement asphalt emulsion mortar with different asphalt to cement ratios and temperatures," Journal of $\mathrm{Ma}$ terials in Civil Engineering, vol. 30, no. 10, Article ID 4018263, 2018.

[19] A. M. Rodríguez-Alloza, J. Gallego, and I. Pérez, "Study of the effect of four warm mix asphalt additives on bitumen modified with 15\% crumb rubber," Construction and Building Materials, vol. 43, pp. 300-308, 2013.

[20] E. Sanchez-Alonso, A. Vega-Zamanillo, D. Castro-Fresno, and M. DelRio-Prat, "Evaluation of compactability and mechanical properties of bituminous mixes with warm additives," Construction and Building Materials, vol. 25, no. 5, pp. 2304-2311, 2011.

[21] J. H. Podolsky, A. Buss, R. C. Williams, and E. W. Cochran, "The rutting and stripping resistance of warm and hot mix asphalt using bio-additives," Construction and Building Materials, vol. 112, pp. 128-139, 2016.

[22] F. Frigio, S. Raschia, D. Steiner, B. Hofko, and F. Canestrari, "Aging effects on recycled WMA porous asphalt mixtures," Construction and Building Materials, vol. 123, pp. 712-718, 2016.

[23] Y. Ye, G. Xu, L. Lou, X. Chen, D. Cai, and Y. Shi, "Evolution of rheological behaviors of styrene-butadiene-styrene/crumb rubber composite modified bitumen after different long-term aging processes," Materials, vol. 12, no. 15, 2345 pages, 2019.

[24] M. Liang, P. Liang, W. Fan et al., "Thermo-rheological behavior and compatibility of modified asphalt with various styrene-butadiene structures in SBS copolymers," Materials \& Design, vol. 88, pp. 177-185, 2015. 